\title{
Previsão de Temperatura da Superfície do Mar (TSM) no Atlântico Tropical com uso de Redes Neurais
}

\author{
Everton Santos Castro $^{1}$ (D), José Maria Brabo Alves ${ }^{2,3}$ (D), Emerson Mariano da Silva ${ }^{2,3}$ (D), \\ José Nilson Campos $^{1}$, Adriano Oliveira Alves ${ }^{2}$ \\ ${ }^{1}$ Departamento de Engenharia Hidráulica e Ambiental, Universidade Federal do Ceará, \\ Fortaleza, CE, Brasil. \\ ${ }^{2}$ Departamento de Física, Universidade Estadual do Ceará, Fortaleza, CE, Brasil. \\ ${ }^{3}$ Mestrado Profissional em Climatologia e Aplicações nos Países da CPLP e África, \\ Universidade Estadual do Ceará, Fortaleza, CE, Brasil.
}

Recebido em: 9 de Fevereiro de 2017 - Revisado em: 28 de Maio de 2020 - Aceito em: 30 de Agosto de 2020

\begin{abstract}
Resumo
Estudos comprovam que a temperatura da superfície do mar nos oceanos tropicais Pacífico e Atlântico é a principal variável física influenciadora das condições climáticas em várias áreas do globo. Assim, as observações e previsões de variáveis oceânicas, como a temperatura da superfície do mar, constituem-se uma ferramenta valiosa para o monitoramento do clima e para um melhor aproveitamento dos recursos naturais, principalmente em regiões que são vulneráveis aos impactos causados pelas mudanças climáticas, como é o caso do Nordeste do Brasil. O presente trabalho tem por objetivo aplicar e avaliar um método que visa utilizar as Redes Neurais Artificiais para prever a temperatura da superfície do mar no oceano Atlântico Tropical e o Gradiente meridional de anomalias de temperatura da superfície do mar no Atlântico Tropical. Os resultados mostraram que as correlações, significativas a 95\% segundo o teste-t de Student, foram melhores para os trimestres FMA e MAM, onde os coeficientes apresentaram valores superiores a 0,75 para algumas regiões do ATN. Para as estimativas do Gradiente Meridional, a RNA apresentou desempenho similar à persistência. Os melhores resultados ocorrem ao se usar a média da TSM do trimestre DJF. Para essa configuração o coeficiente de correlação foi 0,74 .
\end{abstract}

Palavras-chave: previsão de TSM, redes neurais artificiais, Atlântico Tropical.

\section{Forecast of Sea Surface Temperature (SST) in Tropical Atlantic with the use Artificial Neural Networks}

\begin{abstract}
Many studies show that the sea surface temperature in the tropical Pacific and Atlantic oceans is the main influencer physical variable climatic conditions in various areas of the globe. Thus, the observations and forecasts of ocean variables such as sea surface temperature, constitute a valuable tool for climate monitoring and better use of natural resources, particularly in regions that are vulnerable to the impacts of climate change, as is the case of Northeast Brazil. The present work aims to implement and evaluate a method that object to use Artificial Neural Networks to predict the sea surface temperature in the Atlantic Ocean Tropical and the meridional gradient of sea surface temperature anomalies in the Tropical Atlantic. The results showed that the correlations, Significant to $95 \%$ according to the Student t-test, were better for the FMA and MAM quarters, where the coefficients showed values greater than 0,75 for some regions of the ATN. To estimate the Meridional Gradient, the RNA showed similar performance to persistent. The best results occur when using the average of the TSM from the DJF quarter. For this configuration the correlation coefficient was 0,74 .
\end{abstract}

Keywords: SST forecast, artificial neural networks, Tropical Atlantic.

Autor de correspondência: Everton Santos Castro, evertonobf@gmail.com 


\section{Introdução}

As previsões climáticas são ferramentas extremamente úteis para serem usadas no desenvolvimento da sociedade. Muitos aspectos sociais e econômicos são sensíveis às condições meteorológicas. Walker (1928), em trabalho pioneiro sobre os processos de interação oceanoatmosfera em escala global, observou uma relação entre as secas do Nordeste brasileiro e anomalias de Temperatura da Superfície do Mar (TSM) do Oceano Pacífico. Desde então, inúmeras pesquisas foram desenvolvidas com o intuito de compreender como as Anomalias de Temperatura da Superfície do Mar (ATSM) podem interferir nos fenômenos atmosféricos.

Atualmente na literatura, diversos autores apontam que a TSM nos oceanos tropicais Pacífico e Attântico é a principal variável física influenciadora das condições climáticas em várias áreas do globo (Aragão, 1998; Repelli; Nobre, 2004; Andreoli; Kayano, 2005; Alves et al., 2006; Silva et al., 2011).

A variabilidade temporal de TSM no Atlântico tropical foi estudada em diversos trabalhos (Weisberg, 1979; Garzoli, 1987; Zebiak,1993). Tais estudos permitiram observar que a variabilidade da TSM no oceano Attântico Tropical (AT) segue um forte ciclo sazonal que combinado com modos de variabilidade não sazonal exercem grande influência no clima de regiões da América e da África.

Sobrepostos ao ciclo sazonal alguns modos de variabilidade térmica influenciam a Variabilidade do Atlântico Tropical (TAV-Tropical Atlantic Variability). Dentre eles destacam-se o Modo Equatorial, também chamado de El Niño do Atlântico (Zebiak, 1993) e o Modo Meridional, também denominado Gradiente Meridional de TSM ou Dipolo meridional (Moura; Shukla, 1981; Servain, 1991).

O modo equatorial é o principal modo de variabilidade do AT contribuindo com $38 \%$ da variabilidade térmica na bacia. Este modo ocorre com uma frequência de 3 a 8 anos, e está associado com a dinâmica oceânica e a mudança na componente zonal dos ventos alísios na região equatorial (Deser et al., 2010).

O Gradiente Meridional de TSM, segundo modo de variabilidade térmica do AT, é responsável por $25 \%$ da variância térmica na bacia. Caracteriza-se pelo surgimento de um padrão de ATSM configurando-se espacialmente com sinais opostos sobre as Bacias Norte e Sul do AT. O Gradiente Meridional age também no deslocamento da Zona de Convergência Intertropical (ZCIT) do atlântico influenciando as chuvas em regiões da África e da América. Particularmente quando a região norte da bacia se encontra mais quente que a do sul, a ZCIT se posiciona mais ao norte de sua posição normal, ocasionando secas na região Nordeste do Brasil e fortes chuvas na região do Sahel. Quando as águas do hemisfério sul se encontram mais quentes que as do norte, a ZCIT será deslocada mais para o sul, ocasionando chuvas na região
Nordeste do Brasil e secas na região do Sahel (Clauset et al., 2005).

O fato de a TSM ser apontada como a principal forçante influenciadora do clima em varias regiões do globo (Aragão, 1998; Repelli; Nobre, 2004; Andreoli; Kayano, 2005; Alves et al., 2006; Silva et al., 2011) motivou pesquisadores a investigar como a variabilidade da TSM no Atlântico Tropical podem influenciar o clima na região do NEB.

Moura e Shukla (1981) mostram que os eventos de secas do Nordeste brasileiro estão associados ao Gradiente Meridional de anomalias de TSM sobre o Atlântico. Os autores sugerem que as condições dinâmicas e termodinâmicas associadas ao Gradiente Meridional de anomalias de TSM no Atlântico interferem sensivelmente na posição e intensidade da ZCIT (Zona de Convergência Intertropical) e assim influenciando no regime de chuvas. Moura et al. (2009) estudou as relações entre as precipitações na região leste do NEB e a TSM do Atlântico e do Pacífico. Os resultados mostraram que anomalias positivas de TSM no Atlântico Tropical sul produzem precipitação sobre o leste do NEB, enquanto anomalias positivas de TSM no Pacífico inibem a chuva no Leste do NEB. Para Andreoli e Kayano (2007) a variabilidade de TSM do atlântico é a forçante dominante das anomalias de chuva sobre o NEB, e que quando influenciadas pelo Pacífico, as anomalias de precipitação, em determinados momentos podem ser enfraquecidas ou reforçadas.

Dada a influência da TSM sobre o clima de várias regiões do globo, como é o caso do NEB, Repelli e Nobre (2004) afirmam que a confiabilidade da previsão das anomalias sazonais de precipitação para a região será tanto maior quanto melhor forem as previsões das anomalias de TSM sobre os oceanos tropicais. Assim, especificamente, este trabalho tem por objetivo aplicar e avaliar um método que visa utilizar as Redes Neurais Artificiais (RNA) para previsão de TSM e do Gradiente Meridional no Oceano Atlântico Tropical, utilizando como preditores dados de fluxo de calor latente e sensível, pressão do ar ao nível do mar, taxa de evaporação, as componentes zonal e meridional do vento e a própria TSM.

\section{Redes Neurais Artificiais}

As Redes Neurais Artificiais (RNA's) são modelos computacionais baseados no sistema nervoso dos seres vivos. Entre suas características, destacam-se o paralelismo de suas atividades, a alta conectividade e a capacidade elevada em descrever sistemas não-lineares através do método de treinamento, o que permite a rede aprender os comportamentos e extrair o relacionamento existente entre as variáveis envolvidas.

As RNA's podem ser empregadas em diversos problemas tais como ajustes de funções, reconhecimento de 
padrões, modelos de previsão e outras aplicações em diversas áreas do conhecimento humano.

Diante da grande abrangência sobre o assunto e da diversidade de detalhes envolvidos, procurar-se-á focar apenas os aspectos mais importantes das RNA's, enfatizando as informações necessárias para o desenvolvimento desta pesquisa.

\subsection{Neurônios artificiais}

A estrutura das redes neurais artificiais foi desenvolvida a partir do princípio de funcionamento do cérebro humano. Os elementos processadores das redes neurais que tem um papel similar aos neurônios biológicos são chamados de neurônios artificiais.

O modelo de neurônio artificial mais simples, representado na Fig. 1 (Silva et al., 2010, p. 34), foi proposto por McCulloch e Pitts (1943). Conhecido como Perceptron, ele reúne as principais características do neurônio biológico e é o modelo mais utilizado nos mais variados tipos de redes neurais.

No modelo proposto por McCulloch e Pitts, os diversos componentes podem ser comparados aos elementos do neurônio biológico. Os sinais representados pelo conjunto $\left\{X_{1}, X_{2}, \ldots, X_{n}\right\}$ são os dados de entrada advindos do meio externo.

As substâncias neurotransmissoras do neurônio biológico, responsáveis por ponderar a transferência de estímulos de um neurônio para outro, são representadas no neurônio artificial pelo conjunto de pesos sinápticos $\left\{W_{1}, W_{2}, \ldots, W_{3}\right\}$.

\subsection{Perceptron multicamadas (PMC)}

O Perceptron multicamadas, representado na Fig. 2, é uma rede neural multicamadas alimentada adiante, constituído por três camadas: a camada de entrada, cuja função é a de receber as informações externas; uma ou mais camadas intermediárias, também denominadas ocultas, responsáveis pelo aumento da capacidade da rede neural artificial em extrair o comportamento mais complexo a partir dos dados disponíveis utilizados no processo de treinamento; e a camada de saída, cuja função é a de dar as respostas para os estímulos do modelo.

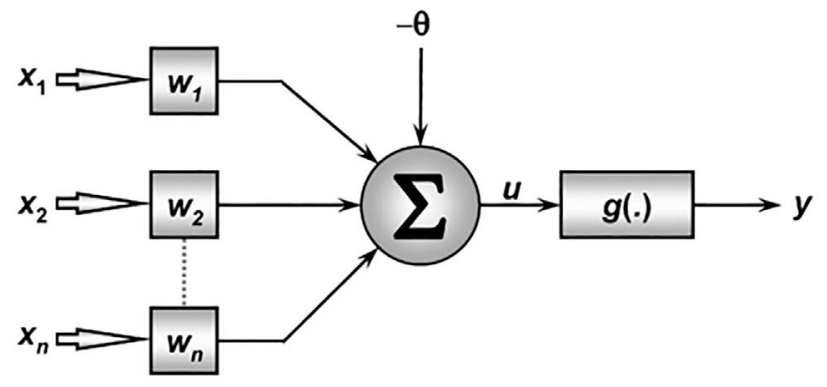

Figura 1 - Neurônio artificial. Fonte: Silva et al. (2010, p. 34).

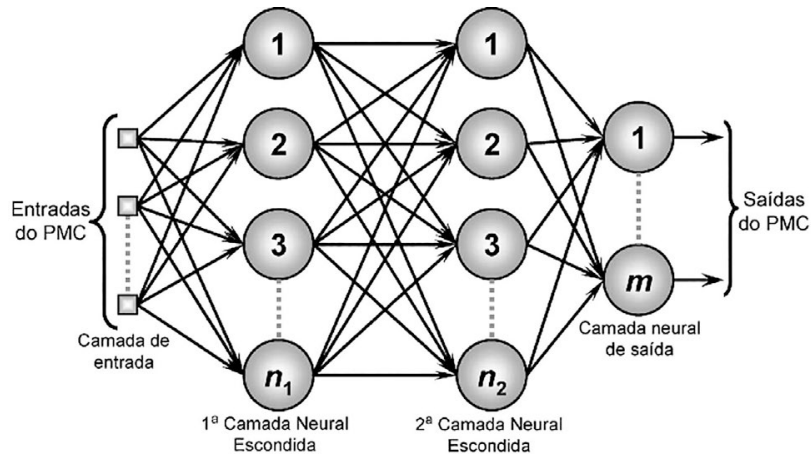

Figura 2 - Representação da rede Perceptron multicamadas. Fonte: Silva et al. (2010, p. 92).

\subsection{Processamento de dados na RNA}

A propriedade primordial de uma rede neural é a sua habilidade de aprender a partir do ambiente e melhorar seu desempenho através da aprendizagem. A aprendizagem da rede neural artificial (fase de treinamento) consiste na alteração de todos os pesos sinápticos e limiares existentes, a partir da experiência conhecida sobre o fenômeno estudado. Esta experiência é representada por um conjunto de dados contendo as entradas e saídas conhecidas para o problema a ser modelado, chamado de conjunto de treinamento. O objetivo do processo de treinamento de uma rede neural é alterar o vetor de pesos sinápticos de forma que o erro seja mínimo.

Após o término do treinamento, pode-se então utilizar as matrizes de pesos sinápticos que foram ajustadas, para estimar a saída do sistema frente às novas amostradas que serão apresentadas em suas entradas. Essa fase chamase de Fase de Operação.

\section{Dados e Metodologia}

Para o desenvolvimento deste trabalho foi utilizada séries de 49 anos (1945-1993) de médias mensais de fluxo de calor latente, fluxo de calor sensível, pressão do ar ao nível do mar, taxa de evaporação, componentes zonal e meridional do vento e medidas de TSM. Os dados foram extraídos da mais nova versão do Comprehensive OceanAtmospheric Data Set (COADS) e estão catalogados no atlas marinho de Silva et al. (1994).

Os dados têm resolução espacial de $1^{\circ}$ de latitude por $1^{\circ}$ de longitude sobre o oceano global, porém para o desenvolvimento deste trabalho são considerados apenas os dados referentes ao oceano Atlântico Tropical que cobre as latitudes de $30^{\circ} \mathrm{S}-30^{\circ} \mathrm{N}$ e de $60^{\circ} \mathrm{W}-15^{\circ} \mathrm{E} \mathrm{em}$ longitude.

\subsection{Pré-processamento e normalização das variáveis}

Para o desenvolvimento dos modelos usando a RNA foi necessário à normalização dos dados utilizados. Esta normalização é necessária uma vez que a função de ativa- 
ção usada pelo neurônio fornece valores dentro de um intervalo. Assim, a normalização tem por finalidade adaptar os dados de entrada à faixa dinâmica da função de ativação. O processo de normalização dos dados foi feito da seguinte forma:

$$
X^{*}=\frac{X_{0}-X_{\min }}{X_{\max }-X_{\min }}
$$

em que $X^{*}$ é a variável normalizada; $X_{0}$ é a variável a ser normalizada; $X_{\min }$ é o valor mínimo da variável a ser normalizada e $X_{\max }$ corresponde ao valor máximo da variável a ser normalizada.

De forma análoga, os valores da camada de saída da rede são recuperados através da seguinte equação:

$$
X=Y\left(X_{\max }-X_{\min }\right)+X_{\min }
$$

em que $X$ é o valor desnormalizado e $Y$ é a saída normalizada da rede.

\subsection{Treinamento e teste da rede neural artificial}

A série temporal utilizada totaliza 49 anos de dados. Para fase de treinamento foi utilizado 23 anos (1945-1967) da série e para a fase de teste utilizou-se os 26 anos restantes (1968-1993).

O interesse do trabalho é estudar a previsibilidade da TSM no AT e do Gradiente Meridional no período de janeiro a maio, com ênfase no trimestre março-abril-maio. Assim, diferentes experimentos foram realizados.

No primeiro experimento foi usada a TSM como variável preditora. Assim a primeira rodada foi realizada com o propósito de se conhecer o desempenho da RNA ao utilizar médias trimestrais da TSM.

Para tanto, ao estimar a média da TSM do trimestre janeiro-fevereiro-março (JFM) no AT, utilizou-se como preditor a média trimestral da TSM de outubro-novembrodezembro (OND) do AT. Para prever a média da TSM do trimestre fevereiro-março-abril (FMA), fez-se uso da média trimestral da TSM de novembro-dezembro-janeiro (NDJ). Para estimar a TSM do trimestre março-abril-maio (MAM), utilizou-se a média da TSM do trimestre anterior, ou seja, dezembro-janeiro-fevereiro (DJF).

No segundo experimento, foram empregadas as variáveis físicas como preditoras para estimar a média da TSM do trimestre MAM. Assim, usou-se a média de cada variável do trimestre DJF.

Devido à relevância do Gradiente Meridional de ATSM no AT para o clima do NEB, o terceiro experimento teve por objetivo estimar o Gradiente Meridional de ATSM no AT no trimestre MAM. Para tanto, usou-se como predidor a média trimestral do próprio Gradiente nos seguintes períodos: DJF, NDJ, OND e SON.

\subsection{Configuração da RNA}

A arquitetura da RNA utilizada foi do tipo perceptron múltiplas camadas e fez-se uso do algoritmo backpropagation para a fase de treinamento.

Como, em geral, não existem regras para a escolha da função de ativação, e alguns parâmetros da estrutura da rede, como o número de camadas ocultas, número de neurônios pertencentes à camada oculta e a taxa de aprendizagem, a escolha foi feita através de tentativa e erro. Dessa forma escolheu-se a configuração que apresentou resultados mais satisfatórios. A função tangente hiperbólica foi escolhida como função de ativação e os demais parâmetros escolhidos para a rede são mostrados na Tabela 1.

\subsection{Métodos estatísticos usados nas análises}

Para a avaliação da previsão de TSM dada pela RNA, os valores previstos foram comparados com os valores de TSM observados e catalogados no atlas marinho de Silva et al. (1994). A saída da RNA também foi comparada com a TSM persistida. Os índices utilizados para analisar o desempenho do modelo são descritos a seguir.

\subsubsection{Coeficiente de correlação de Pearson (r)}

Avalia o grau de relacionamento entre as variáveis e é definido por:

$$
r=\frac{1}{n-1} \sum_{i=1}^{n}\left(\frac{y_{i}-\bar{y}}{S_{y}}\right)\left(\frac{d_{i}-\bar{d}}{S_{d}}\right)
$$

em que $S_{y}, S_{d}, y_{i}, d_{i}$ correspondem ao desvio padrão da saída da RNA, desvio padrão do campo de TSM observada, saída da RNA, TSM observada respectivamente. $\bar{y} \mathrm{e}$ $\bar{d}$ correspondem, respectivamente às médias da saída da RNA e da TSM observada e $n$ é o número de observações.

$\mathrm{O}$ valor de $r$ pode variar de -1 a 1, sendo assim, para uma relação positiva perfeita, deve-se ter $r=1$. Para uma relação negativa perfeita, deve-se ter $r=-1$. Para $r=0$ a relação é difusa ou não linear.

\subsubsection{Teste t de Student ( $t)$}

Comprova se o coeficiente de correlação encontrado é significativo. O teste de significância t-Student foi aplicado levando em consideração a correlação das séries para

Tabela 1 - Configuração da RNA na fase de treinamento.

\begin{tabular}{lcc}
\hline Parâmetros & $\begin{array}{c}\text { Preditor } \\
\text { (TSM) }\end{array}$ & $\begin{array}{c}\text { Preditor (variáveis } \\
\text { físicas) }\end{array}$ \\
\hline $\begin{array}{l}\text { Número de neurônios na camada } \\
\text { de entrada }\end{array}$ & 01 & 05 \\
$\begin{array}{l}\text { Número de camadas ocultas } \\
\text { Número de neurônios na camada }\end{array}$ & 01 & 01 \\
oculta & 03 & 10 \\
Taxa de aprendizagem & 0,1 & 0,1 \\
\hline
\end{tabular}


o nível de significância de $95 \%$. A estatística do teste t é definida por:

$$
t_{c}=\frac{r \sqrt{n-2}}{\sqrt{1-r^{2}}}
$$

em que $r$ é a correlação encontrada e $n$ é o número de dados. As hipóteses do teste são:

$$
\begin{aligned}
& H_{0}: \rho=0 \\
& H_{1}: \rho \neq 0
\end{aligned}
$$

em que $H_{0}$ é a hipótese nula, ou seja, não existe correlação entre a variável analisada (TSM estimada) e a TSM observada e $H_{1}$ é a hipótese alternativa, ou seja, existe correlação entre as variáveis.

\subsubsection{Erro absoluto médio: (MAE-mean absolute error)}

Índice que mede a magnitude média dos erros de previsão. Possui a mesma unidade das previsões ou das observações e seu valor para previsão perfeita é 0 . O MAE é definido por:

$$
M A E=\frac{1}{N} \sum_{i=1}^{N}\left(y_{i}-d_{i}\right)
$$

em que $y_{i}$ e $d_{i}$ é a TSM simulada e observada, respectivamente num domínio numérico de $N$ pontos.

\subsubsection{Erro quadrático médio: (MSE-mean square error)}

Similar ao MAE, porém mais sensível aos grandes erros, por elevar as diferenças individuais ao quadrado. $\mathrm{O}$ MSE é sempre positivo e para uma simulação perfeita o $\mathrm{MSE}=0$. O MSE é definido por:

$$
M S E=\frac{1}{N} \sum_{i=1}^{N}\left(y_{i}-d_{i}\right)^{2}
$$

\section{Resultados e Discussões}

A seguir apresentam-se os resultados das previsões de TSM obtidas pela RNA. Primeiramente será apresentada a previsão, onde foi utilizada a própria TSM como variável preditora, em seguida, é apresentado os resultados para a previsão da TSM tendo como preditor as variáveis físicas.

A Fig. 3 apresenta as correlações entre a média da ATSM do trimestre JFM estimada pela RNA e a média da ATSM observada e entre a ATSM persistida e a observada. Durante a fase de treinamentos, a RNA foi alimentada com a média da TSM do trimestre OND. Na persistência, considerou-se que a média da ATSM do trimestre OND seria a mesma para o trimestre JFM.

Observa-se que a estimativa realizada pela RNA (Fig. 3a) possui correlações significativas em algumas áreas do AT. Para o ATN as áreas com correlações significativas apresentaram índices variando entre 0,4 e 0,6. A persistência (Fig. 3b) apresentou áreas de correlações significativas praticamente para toda a bacia do AT. As correlações variaram de 0,35 a 0,8 . Vale ressaltar que a área em branco, não indica a ausência de correlações, mas que as correlações não possuem confiança, de acordo com o teste $t$, acima de $95 \%$.

As correlações para o trimestre FMA são mostradas na Fig. 4. Os índices são entre a média da ATSM do trimestre FMA estimada pela RNA e a média da ATSM observada, e entre a ATSM persistida e a observada. Na persistência, considerou-se que a média da ATSM do trimestre NDJ seria a mesma para o trimestre FMA. Durante a fase de treinamentos, a RNA foi alimentada com a média da TSM do trimestre anterior ao trimestre da previsão.

As correlações entre a estimativa realizada pela RNA e a observada (Fig. 4a) mostrou-se melhor em relação a persistência para a faixa do atlântico equatorial entre 0 e $10^{\circ} \mathrm{N}$ apresentando uma maior área significativa. Os melhores resualtados, novamente foram para o ATN. Para o ATS, maior parte da bacia não apresentou, segundo o teste-t, correlações com nível confiança superiores a 95\%.

A Fig. 5 apresenta os índices do erro absoluto e erro quadrático entre a estimativa realizada pela RNA e a
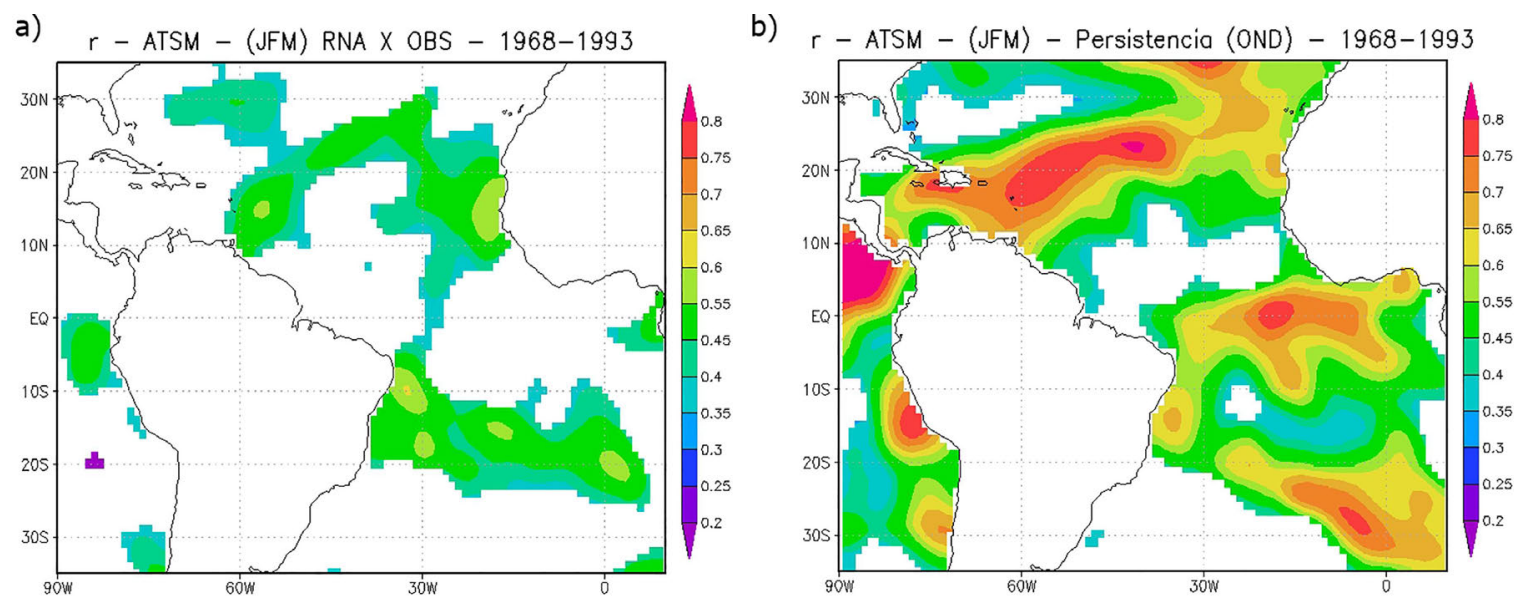

Figura 3 - (a) Correlação entre a ATSM estimada pela RNA e a ATSM observada; (b) Correlação entre a ATSM observada e a ATSM persistida. 
ATSM observada, e entre a persistência e a ATSM observada. Os índices são para a média do trimestre FMA e a persistência é a média do trimestre NDJ.

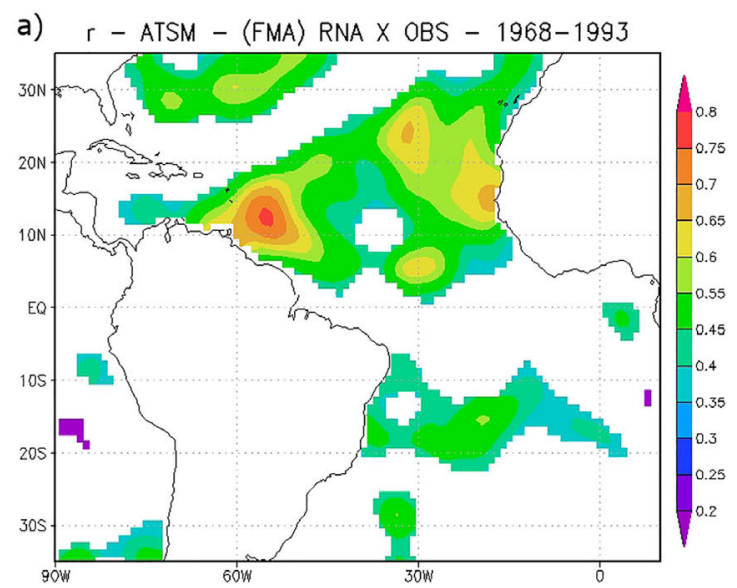

Para o trimestre FMA, a estimativa realizada pela RNA e a ATSM persistida apresentaram tanto MAE quanto o MSE bem similares no ATN, foi também para

b)

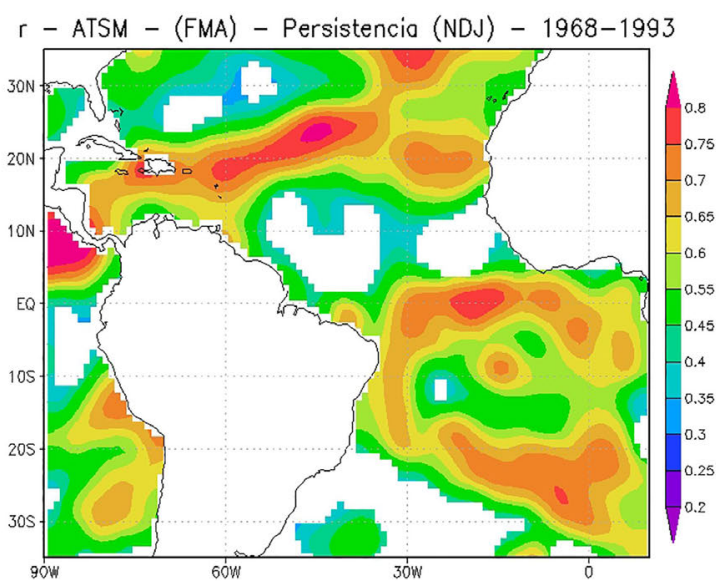

Figura 4 - (a) Correlação entre a ATSM estimada pela RNA e a ATSM observada; (b) Correlação entre a ATSM observada e a ATSM persistida. As áreas plotadas indicam significância de $95 \%$ segundo teste t Sudent.

a) MAE-ATSM (FMA) RNA X OBS - 1968-1993

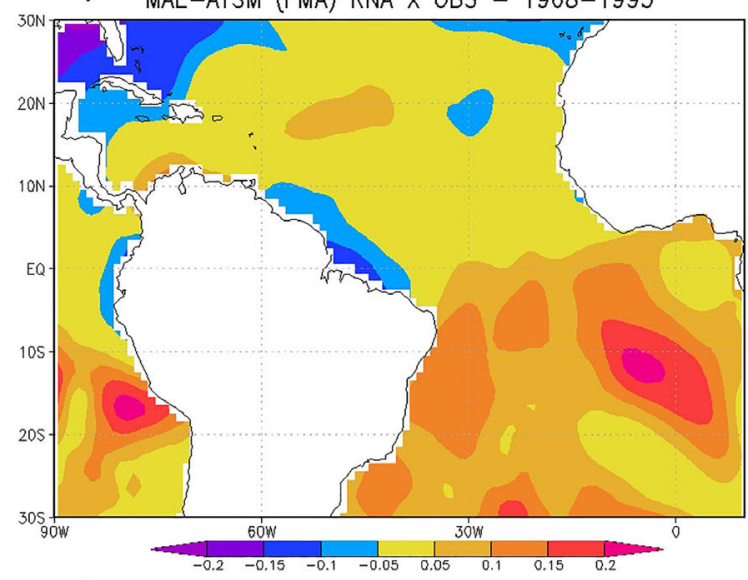

c)

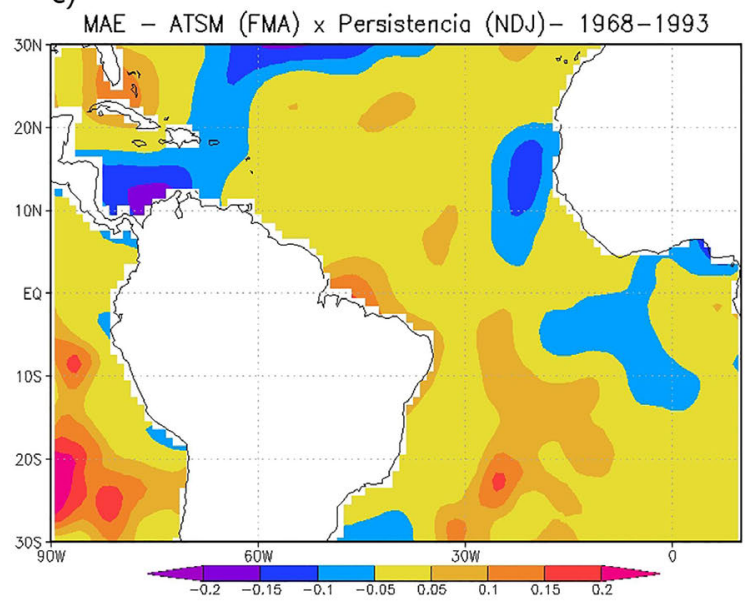

b)

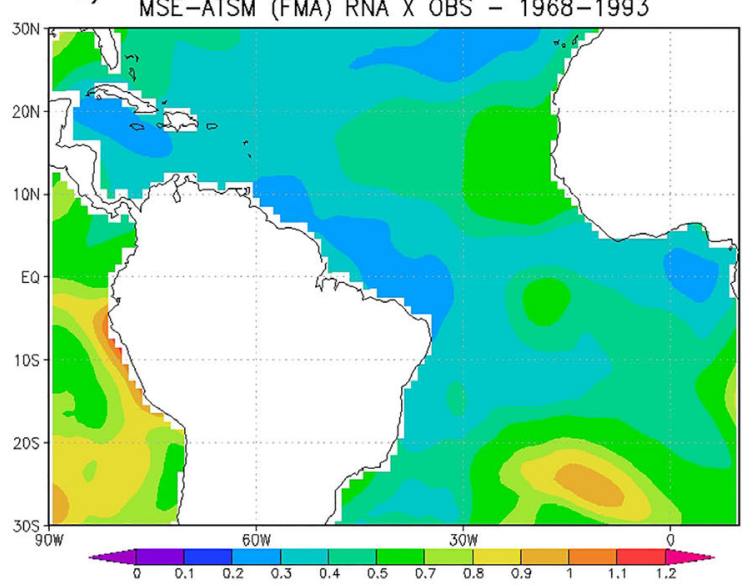

d)

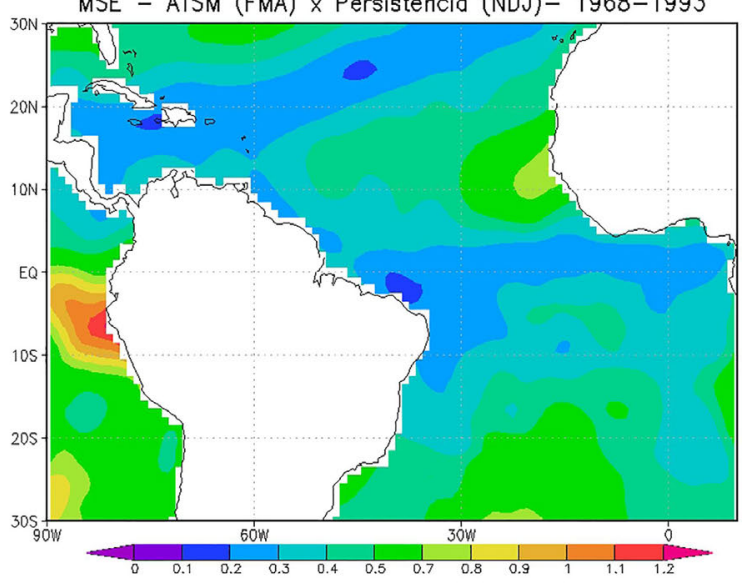

Figura 5 - (a) MAE entre a ATSM (RNA) e a ATSM observada; (b) MSE entre a ATSM (RNA) e a ATSM observada; (c) MAE entre a ATSM observada e a ATSM persistida; (d) MSE entre a ATSM observada e a ATSM persistida. Erros em ${ }^{\circ} \mathrm{C}$. 
esta bacia onde os erros apresentaram os menores índices, com destaque a faixa compreendida entre $5^{\circ}-20^{\circ} \mathrm{N}$ e $30^{\circ}-$ $15^{\circ} \mathrm{W}$ onde a RNA apresentou o MAE inferior quando comparado à persistência. Para previsão realizada pela
RNA, os maiores erros ocorreram na faixa leste do ATS, onde o MAE foi superior a $0,2^{\circ} \mathrm{C}$.

As correlações para o trimestre MMA são mostradas na Fig. 6. Os índices são entre a média da ATSM do tri-
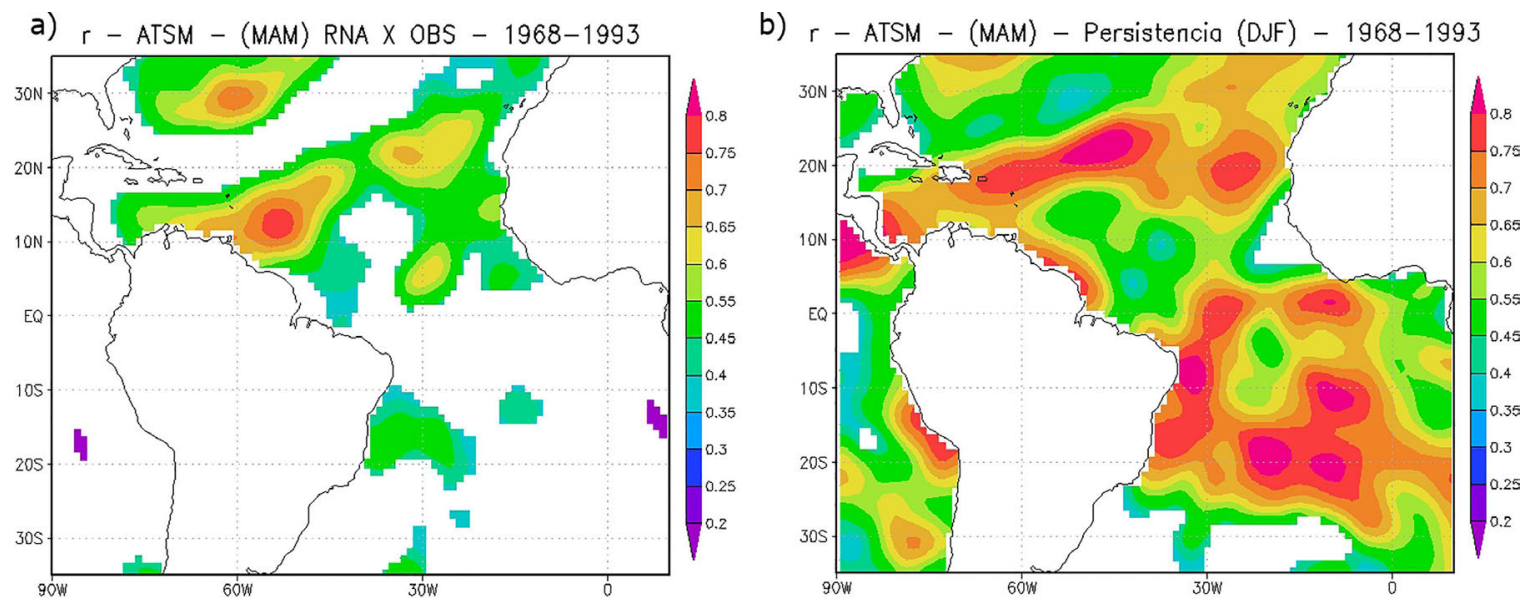

Figura 6 - (a) Correlação entre a ATSM estimada pela RNA e a ATSM observada; (b) Correlação entre a ATSM observada e a ATSM persistida. As áreas plotadas indicam significância de $95 \%$ segundo teste t Sudent.

a) MAE-ATSM (MAM) RNA $\times$ OBS - 1968-1993

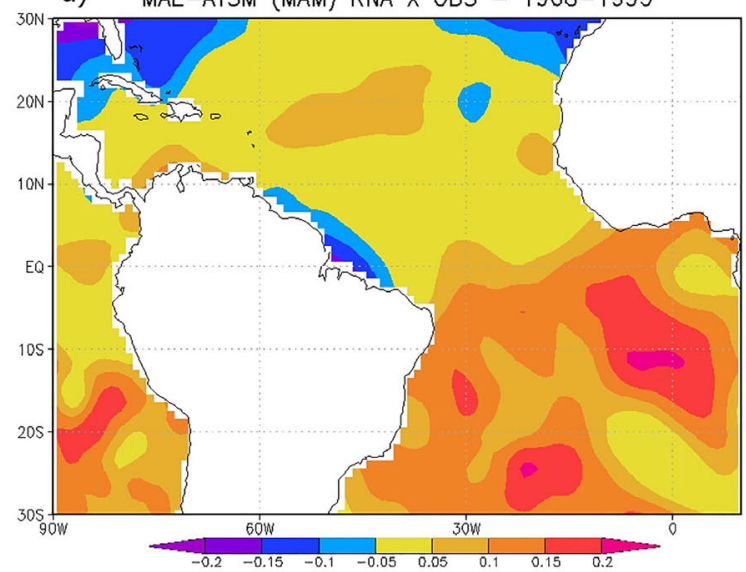

c)

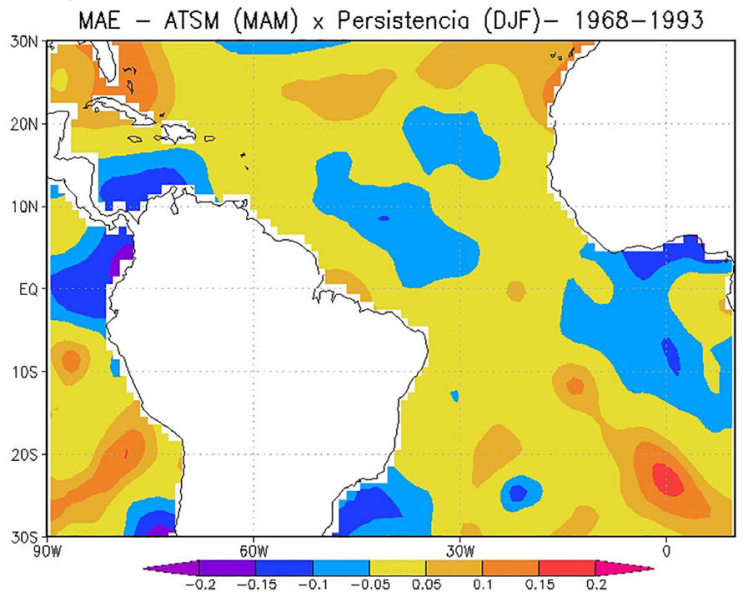

b) MSE-ATSM (MAM) RNA X OBS - 1968-1993

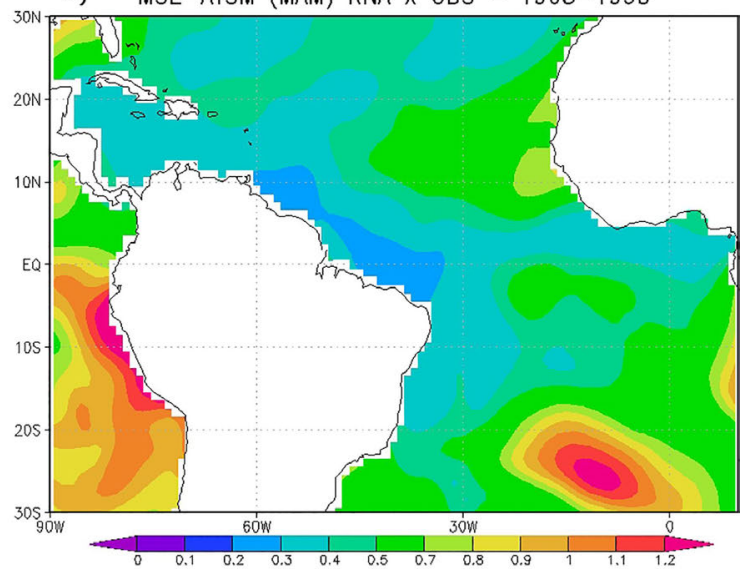

d)

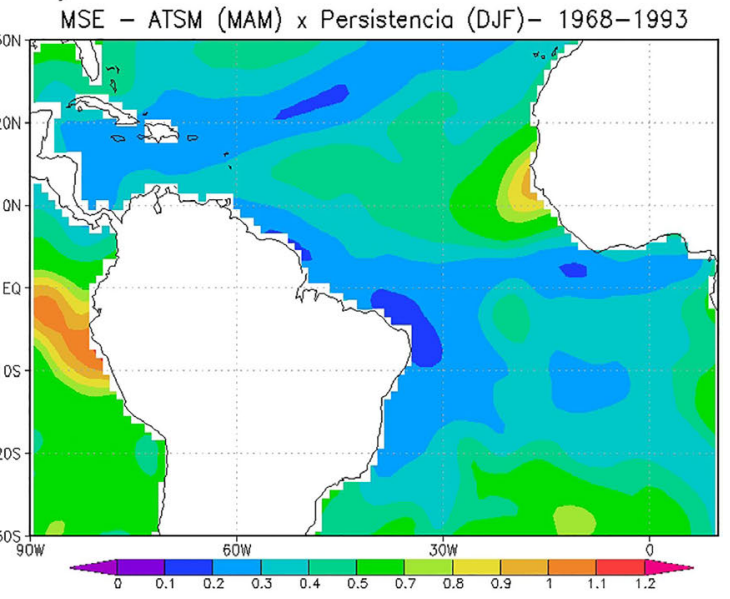

Figura 7 - (a) MAE entre a ATSM (RNA) e a ATSM observada; (b) MSE entre a ATSM (RNA) e a ATSM observada; (c) MAE entre a ATSM observada e a ATSM persistida; (d) MSE entre a ATSM observada e a ATSM persistida. Erros em ${ }^{\circ} \mathrm{C}$. 
mestre MAM estimada pela RNA e a média da ATSM observada, e entre a ATSM persistida e a observada. Para a fase de treinamento, a RNA foi alimentada com a média da TSM do trimestre DJF. Na persistência, considerou-se que a média da ATSM do trimestre DJF seria a mesma para o trimestre MAM.

As estimativas da RNA para o trimestre MAM novamente apresentaram melhores correlações sobre a região norte da bacia do Attântico com correlações variando entre 0,4 e 0,8 . Para o ATS, poucas áreas mostraram-se representativas. A persistência, por sua vez, mostrou-se eficiente apresentando correlações superiores a $0,75 \mathrm{em}$ parte do ATN e para uma grande parte do ATS.

A Fig. 7 apresenta os índices do erro absoluto e erro quadrático entre a estimativa realizada pela RNA e a ATSM observada, e entre a persistência e a ATSM observada. Os índices são para a média do trimestre MAM e a persistência é a média do trimestre DJF.
Novamente, percebe-se que a RNA teve dificuldades em representar a região do ATS, apresentando MAE (Fig. 7a) variando de $-0,05$ a $0,2{ }^{\circ} \mathrm{C}$. Outro fato notado é que para todos os períodos analisados, a RNA representou com mais eficiência o ATN e tendeu a superestimar a TSM no ATS.

Ainda que em muitos casos o desempenho da RNA tenha se mostrado comparável ou inferior à persistência, vale salientar que os campos previstos pelo modelo não foram submetidos a nenhum fator de ajustes para a correção da magnitude da TSM prevista.

A seguir (Fig. 8) são apresentadas as estimativas da média trimestral da TSM para o trimestre MAM usando como preditores o fluxo de calor latente, fluxo de calor sensível, taxa de evaporação, pressão ao nível do mar e velocidade do vento. As variáveis preditoras são relativas à média de cada variável no trimestre DJF.

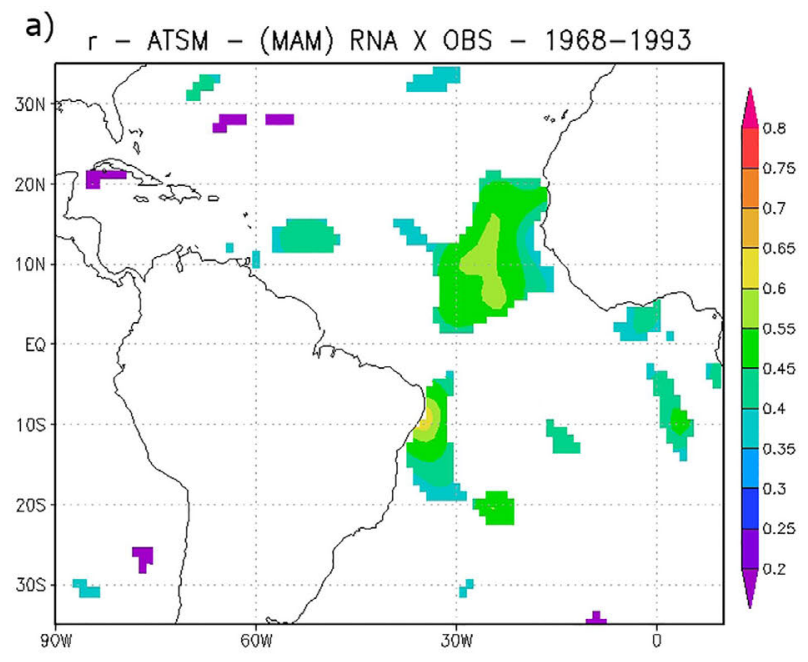

b) MAE-ATSM (MAM) RNA $\times$ OBS - 1968-1993

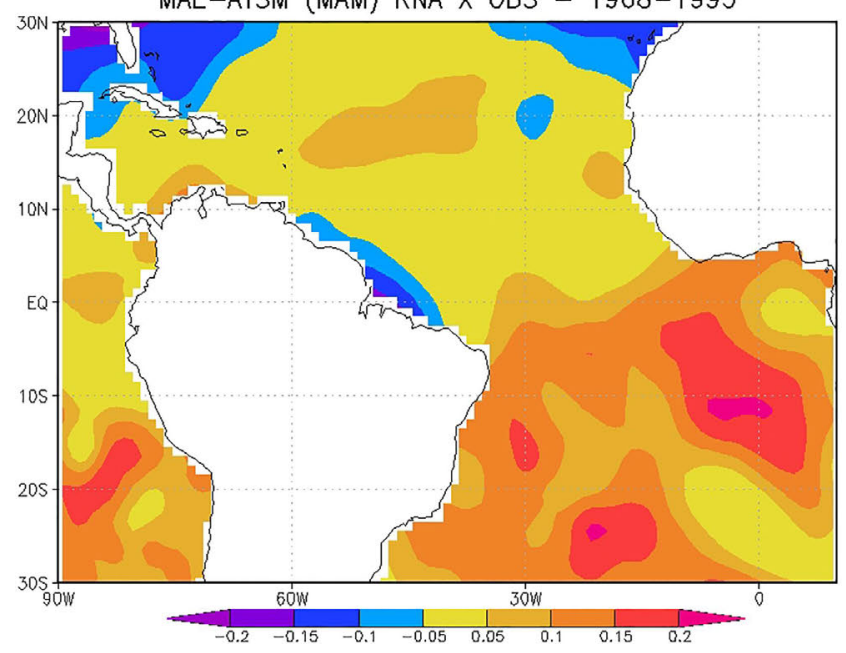

c) MSE-ATSM (MAM) RNA X OBS - 1968-1993

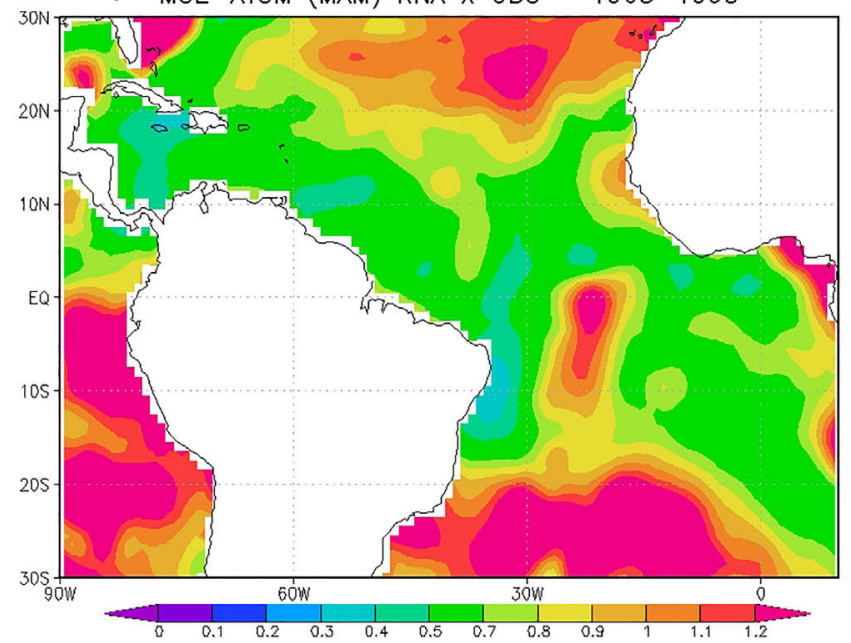

Figura 8 - Estimativa da RNA para o trimestre MAM usando como preditores as variáveis físicas. a) Correlação entre a ATSM prevista e a observada. b) Erro absoluto médio; c) Erro quadrático médio. As áreas plotadas indicam significância de $95 \%$ segundo teste t Sudent. Erros em ${ }^{\circ} \mathrm{C}$. 
As correlações (Fig. 8a) mostram-se representativas para alguns pontos da bacia, com ênfase na parte leste do ATN, onde o coeficiente de correlação variou entre 0,45 e 0,6 .

Apesar de maior parte da bacia não apresentar coeficientes no nível de significância, segundo o teste-t, superiores a 95\%, os índices do MAE e do MSE para previsão da RNA quando se utiliza as variáveis físicas como preditoras, apresentou valores satisfatórios. Novamente os menores erros ocorreram para o ATN, no qual erro absoluto variou aproximadamente $0,1{ }^{\circ} \mathrm{C}$ praticamente para toda bacia.

A seguir serão apresentas as estimativas do Gradiente Meridional de Temperatura do Atlântico feita pela RNA. As estimativas são para o trimestre MAM usando como preditores a média trimestral de DJF, NDJ, OND e SON.

Para todos os períodos de previsão a estimativa realizada pela RNA tende a subestimar o dipolo meridional. A RNA teve um melhor desempenho ao se utilizar a média do trimestre MAM como preditores.

A estimativa do Dipolo Meridional, ao se utilizar DJF no campo preditor, é mostrada na Fig. 9a. A amplitude do dipolo (observado) foi de aproximadamente $1,6^{\circ} \mathrm{C}$ enquanto para a RNA, foi de $1{ }^{\circ} \mathrm{C}$ e da persistência foi de $0,8{ }^{\circ} \mathrm{C}$. A RNA teve um desempenho superior à persistência nos anos de 1971, 1974, 1975, 1982, 1985, 1986,1989 e 1991.

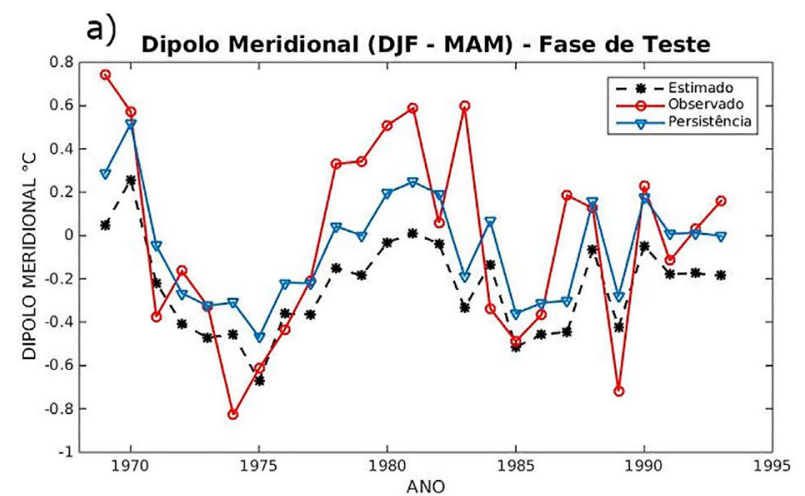

c)

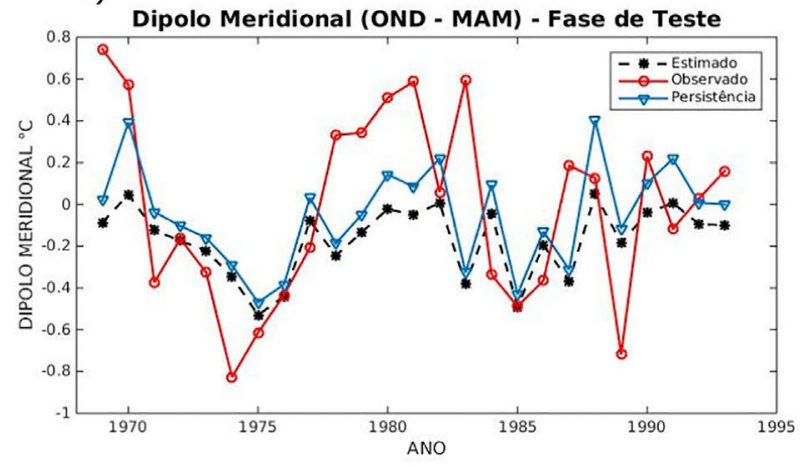

A Tabela 2 mostra as correlações, o erro absoluto médio $\left({ }^{\circ} \mathrm{C}\right)$ e o erro quadrático médio $\left({ }^{\circ} \mathrm{C}\right)$ entre a estimativa realizada pela RNA e o dipolo observado, e entre a persistência e o dipolo observado.

Observa-se que para todos os campos preditores, as correlações entre a estimativa da RNA e o Dipolo observado e entre a persistência e o Dipolo observado são semelhantes. A persistência tem desempenho superior a RNA quando se compara os erros absolutos e quadráticos. Na melhor rodada da RNA, quando se utilizou como preditor a média do trimestre DJF, os erros absolutos e quadráticos foram de 0,22 e 0,15 respectivamente, enquanto que para a persistência, os mesmos apresentaram valores de 0,04 e 0,10 . Na fase de treinamento, etapa pela qual os

Tabela 2 - Desempenho da RNA na previsão do Gradiente Meridional.

\begin{tabular}{lccccc}
\hline \multicolumn{1}{c}{ Fase } & Índice & DJF & NDJ & OND & SON \\
\hline \multirow{4}{*}{ Treinamento } & $\mathrm{R}$ & 0,76 & 0,63 & 0,57 & 0,40 \\
\multirow{4}{*}{ Teste } & MAE & 0,01 & 0,01 & 0,02 & 0,05 \\
& MSE & 0,05 & 0,07 & 0,08 & 0,10 \\
& $\mathrm{R}$ & 0,74 & 0,52 & 0,45 & 0,41 \\
& MAE & 0,22 & 0,34 & 0,15 & 0,16 \\
\multirow{4}{*}{ Persistência } & MSE & 0,15 & 0,27 & 0,18 & 0,18 \\
& R & 0,74 & 0,52 & 0,45 & 0,45 \\
& MAE & 0,04 & 0,03 & 0,03 & 0,02 \\
& MSE & 0,10 & 0,14 & 0,15 & 0,15 \\
\hline
\end{tabular}

b)

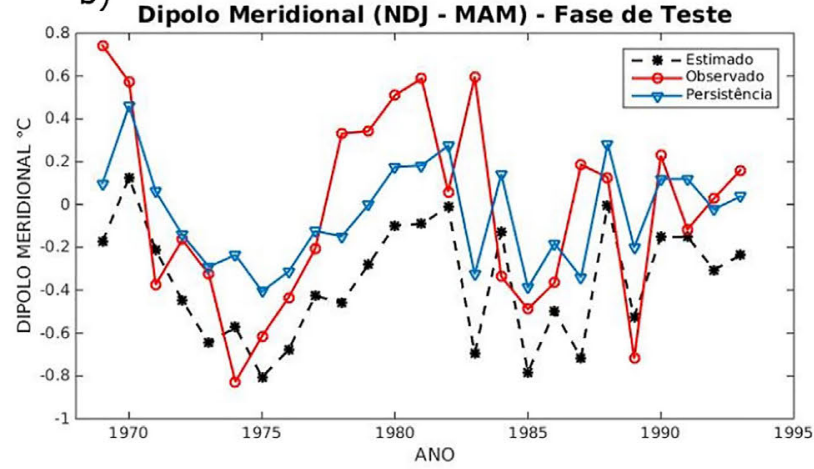

d) Dipolo Meridional (SON - MAM) - Fase de Teste

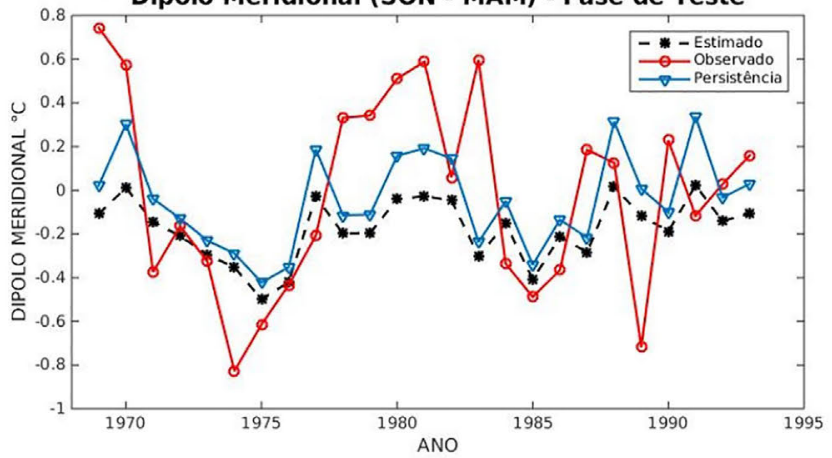

Figura 9 - Média do dipolo meridional para o trimestre MAM usando como preditores: a) DJF, b) NDJ, c) OND, d) SON. 
pesos sinápticos são ajustados, os erros absolutos médios e quadráticos médios são inferiores a 0,05 e 0,10 respectivamente, sugerindo que a rede se aproxima do seu limite de previsão diante das informações que lhe foram passadas na fase de aprendizagem.

\section{Conclusões}

Modelo de previsão usando Redes Neurais Artificiais foi desenvolvido para estimar campos de TSM no Atlântico Tropical. Como preditores, usou-se médias trimestrais de TSM e um conjunto de variáveis físicas (fluxo de calor latente, fluxo de calor sensível, pressão ao nível do mar, taxa de evaporação e as componentes zonal e meridional do vento). O desempenho do modelo é investigado para os trimestres JFM, FMA e MAM comparando as estimativas realizadas pelo modelo com os valores observados, com a persistência.

Também se utilizou a RNA para estimar o Gradiente Meridional de Temperatura do AT no trimestre MAM. Para tanto, foi utilizado a TSM com variável preditora com defasagem de até 3 meses.

Ao se utilizar os campos de TSM como variável preditora, as estimativas para o ATN foram melhores do que as obtidas para o AE e o ATS. A tendência do ATN ser mais representativo e de mais fácil previsão também foi notada em trabalhos anteriores como Andreoli e Kayano (2005), Repelli e Nobre (2004) e Penland e Matrosova (1998). Isto sugere que TSM no ATS depende mais de fatores locais, como as variações atmosféricas ou a própria dinâmica oceânica na escala sazonal.

As melhores correlações, no nível de confiança de 95\% segundo o teste-t de student, foram para os trimestres FMA e MAM, onde os coeficientes apresentaram valores superiores a 0,75 para algumas regiões do ATN. O MAE e MSE também apresentaram valores satisfatórios. Para o trimestre FMA o MAE variou entre $-0,05$ e $0,05{ }^{\circ} \mathrm{C}$ praticamente para todo o ATN, e o MSE variou entre 0,2 e $0,4{ }^{\circ} \mathrm{C}$ praticamente para toda a bacia do AT.

Para as estimativas do Gradiente Meridional, a RNA apresentou desempenho similar à persistência. Os melhores resultados ocorrem ao se utilizar a média do trimestre DJF no campo preditor, o coeficiente de correlação para esta configuração foi 0,74 , o MAE e o MSE foram de $0,22{ }^{\circ} \mathrm{C}$ e $0,15^{\circ} \mathrm{C}$, respectivamente.

O exercício de previsão e comparação com as observações para o AT no período de JFM, FMA e MAM sugerem que a RNA apresenta uma boa potencialidade para ser usada na previsão de TSM sobre o AT, bem como para estimar o Gradiente Meridional de Temperatura sobre a bacia AT. Porém essa potencialidade de previsão pode ser explorada para outras situações climáticas, bem como ser estendida para outros períodos do ano.

A RNA tende a assimilar os padrões do problema proposto durante a fase de treinamento baseando-se nas informações que são dadas à rede durante esta fase, assim a inclusão de mais informações, como TSM sobre o Pacífico, períodos mais longos no campo de preditores têm o potencial de melhorarem o desempenho da RNA.

\section{Refêrencias}

ARAGÃO, J.O.R. O impacto do ENSO e do Dipolo do Atlântico no Nordeste do Brasil. Bulletin the l'Institut Français d'Études Andines, v. 27, n. 3, p. 839-844, 1998.

ANDREOLI, R.V.; KAYANO, M.T. Previsões de anomalias de temperatura da superfície do mar no atlântico tropical usando análises de correlações canônicas. Revista Brasileira de Meteorologia, v. 20, n. 1, p. 93-104, 2005.

ALVES, J.M.B.; SOUZA, R.O.; CAMPOS, J.N.B. Previsão da anomalia de temperatura da superfície do mar (TSM) no atlântico tropical, com equação da difusão de temperatura. Revista Climanálise, v. 1, n. 3, p. 6-19, 2006.

ANDREOLI, R.V.; KAYANO, M.T. A importância relativa do Atlântico tropical sul e Pacífico leste na variabilidade de precipitação do Nordeste do Brasil. Revista Brasileira de Meteorologia, v. 22, n. 1, p. 63-74, 2007.

CLAUZET, G.; WAINER, I.; SERVAIN, E.J. A variabilidade oceânica e atmosférica na região do Atlântico tropical nos dados da rede pirata a partir da análise de ondeletas. Revista Brasileira de Meteorologia, v. 20, n. 1, p. 43-58, 2005.

DESER, C.; ALEXANDER, M.A.; XIE, S.P.; PHILLIPS, A.S. Sea Surface Temperature Variability: Patterns and Mechanisms. Annual Review of Marine Science, v. 2, n.1, p. $115-143,2010$.

GARZOLI, S.L. Forced oscillations on the equatorial Atlantic basin during the seasonal response of the equatorial Atlantic program (1983-1984). Journal of Geophysical Research, v. 92, n. 5, p. 5089-5100, 1987.

MOURA, A.D.; SHUKLA, J. On the dynamics of drougths in northeast Brazil: observations, theory and numerical experiments with a general circulation model. Journal of the Atmosferic Sciences, v. 38, n. 12, p. 2653-2675, 1981.

MOURA, G.B.A.; ARAGÃO, J.O.R.; MELO, J.S.P.; SILVA, A.P.N.; GIONGO, P.R.; LACERDA, F.F. Relação entre a temperatura do leste do Nordeste do Brasil e a temperatura dos oceanos. Revista Brasileira de Engenharia Agrícola e Ambiental, v. 13, n. 4, p. 462-469, 2009.

MCCULOCH, W.S.; PITTS, W. A logical calculus of the ideias imanente in nervous activity. Bullentin of Mathematical Biophysics, v. 5, n. 4, p. 115-133, 1943.

PENLAND, C.; MATROSOVA, L. Prediction of tropical atlantic sea surfasse temperatures using linear inverse modeling. Journal of Climate, v. 11, n. 3, p. 483-493, 1998.

REPELLI, C.A.; NOBRE, P. Statistical prediction of sea-surface temperature over the tropical atlantic. International Journal of Climatology, v. 24, n. 1, p. 45-55, 2004.

SILVA, A.P.N.; MOURA, G.B.A.; GIONGO, P.R.; MEDEIROS, S.R.R. Correlação entre as temperaturas da superfície do mar e a quantidade da precipitação na estação chuvosa no nordeste do estado de Pernambuco. Revista Brasileira de Meteorologia, v. 26, n.1, p. 149-156, 2011. 
SERVAIN, J. Simple climatic índices for the tropical atlantic ocean and some applications. Journal of Geophysical Research, v. 96, n. C8, p. 15137-15146, 1991.

SILVA, I.N.; SPATTI, D.H.; FLAUZINO, R.A. Redes Neurais Artificiais para Engenharia e Ciencias Aplicadas. Sao Paulo: Artliber, 2010.

SILVA, A.M.; YOUNG, C.C.; LEVITUS, S. Atlas of Surface Marine Data 1994. Algorithms and Procedures, v. 1, n. 6, 1994.

WALKER, G.T. Ceará (Brazil) famines and the general air movement. Beitrage zur Physik der freien Atmosphare, v. 14, p. 88-93, 1928.
WEISBERG, R.H. Equatorial waves during GATE and their relation to the mean zonal circulation. Deep Sea Research, v. 26, n. 1, p. 179-198, 1979.

ZEBIAK, S.E. Air-sea interaction in the equatorial Atlantic region. Journal Climate, v. 6, n. 8, p. 1567-1586, 1993.

License information: This is an open-access article distributed under the terms of the Creative Commons Attribution License (type CC-BY), which permits unrestricted use, distribution and reproduction in any medium, provided the original article is properly cited. 